\title{
Literatura infantil, Educação Ambiental e as possibilidades acadêmicas
}

\section{Children's Literature, Environmental Education and Academic Possibilities}

Nathana Pizzolato Minuzzi

ORCID: https://orcid.org/0000-0003-1303-9337 Universidade Regional Integrada do Alto Uruguai e das Missões - URI, Brasil E-mail: nathanaaminuzzi@gmail.com

Cisnara Pires Amaral

ORCID: https://orcid.org/0000-0002-5510-5710 Universidade Regional Integrada do Alto Uruguai e das Missões - URI, Brasil E-mail: cisnara.amaral@urisantiago.br

Article Info:

Article history: Received 2021-10-20

Accepted 2021-11-02

Available online 2021-11-30

doi: $10.18540 /$ revesvl5iss1pp13525-01-07e

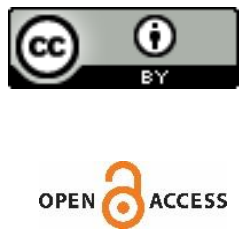

Resumo. A atividade traz a percepção de acadêmicos em relação a exploração da Educação Ambiental através da literatura infantil, com a produção de uma obra infanto juvenil, servindo como estratégia para produção de recursos didáticos que envolvessem criatividade, conhecimento científico, curiosidade e percepção em relação as questões ambientais. Compreendemos a importância de novas metodologias como ferramentas estratégicas para que o ensino de Ciências se torne mais dinâmico, atrativo e empolgante. Assim, ocorreu a produção do livro, como atividade de extensão relacionado a disciplina de Laboratório de Ensino de Ciências Naturais, intitulado "Uma história nada comum: viaje no mundo dos vertebrados". Para a avaliação da atividade, os acadêmicos responderam a um questionário de satisfação em relação a sua produção. Notou-se que os acadêmicos compreendem a importância de diferentes metodologias para que o ensino de Ciências se torne mais prazeroso, e citam a eficácia da utilização da Literatura como meio para tornar as aulas mais significativas; reconhecem a Educação Ambiental como ferramenta para desenvolver o respeito pelas diferentes formas de vida, a compreensão da importância da biodiversidade e da preservação ambiental, salientando que novas metodologias se bem planejadas contribuem para o aprendizado.

Palavras-chave: Literatura infantil; Proposta Pedagógica; Educação Ambiental.

Abstract. The activity brings the perception of academics in relation to the exploration of Environmental Education through children's literature, with the production of a book for young children, serving as a strategy for the production of didactic resources that involve creativity, scientific knowledge, curiosity and perception in relation to environmental issues. We understand the importance of new methodologies as 
strategic tools for science teaching to become more dynamic, attractive and exciting. Thus, the book was produced as an extension activity related to the discipline of Laboratory of Teaching of Natural Sciences, entitled "A story not common: travel in the world of vertebrates". To evaluate the activity, the students answered a satisfaction questionnaire related with their production. It was noted that the students understand the importance of different methodologies for the teaching of Sciences becomes more pleasurable, and they cite the effectiveness of the use of literature as a mean to make classes more meaningful; recognize Environmental Education as a tool to develop respect for different forms of life, understanding the importance of biodiversity and environmental preservation, emphasizing that new methodologies, if well planned, can contribute for the learning.

Keywords: Children's Literature; Pedagogical Proposal; Environmental Education.

\section{Introdução}

Percebe-se a importância da Educação Ambiental (EA) na escola, principalmente em relação a mudança de hábitos e atitudes, contribuindo para a formação de discentes críticos, participativos e cientes em relação aos desequilíbrios ambientais e suas consequências. Imagine então, atrelar a literatura a possibilidade de exercer a cidadania, através de histórias infantis?

Nesse contexto, se encontram acadêmicos matriculados nos cursos de Licenciatura, que compreendem a importância da leitura e da escrita, como método capaz de auxiliar a investigação, instigar a curiosidade e contribuir para a aquisição de conhecimentos. Essa união entre Literatura e Ciência possibilita ao homem conhecer, imaginar, criar. Como resultado ele compreende, questiona, se posiciona, transforma (GROTO, 2012).

Groto (2012) observa "se a Literatura for bem trabalhada, enriquece a imaginação da criança e oferece-lhe condições de uma visão mais ampla do mundo em que vivemos".

Corroboram Patriarcha-Graciolli e Zanon (2021) a leitura tem um papel importante na formação do sujeito, pois contribui para sua formação reflexiva e transformadora, visto que, a criança ao ser inserida no mundo da leitura faz descobertas e posteriormente amplia a compreensão de si e do mundo que a cerca.

Dessa forma, a interdisciplinaridade entre essas duas disciplinas contribuirá para o encantamento, imaginação, capacidade de crítica e autocrítica e sensibilização em relação a EA relacionada aos desequilíbrios vivenciados cotidianamente. Pelicioni e Philippi Jr (2009, p. 3), enfatizam que a Educação Ambiental " irá formar e preparar cidadãos para a reflexão crítica e para uma ação social corretiva ou transformadora do sistema, de forma a tornar viável o desenvolvimento integral dos seres humanos".

Sabemos a importância desse processo, pois a leitura aproxima o indivíduo da percepção de si e do mundo, favorece o encantamento pelo mundo do faz de conta. Soma-se a isso o olhar atendo do professor em organizar as literaturas que serão trabalhadas durante o currículo escolar, o que deve ser planejado de forma interdisciplinar, de maneira que não seja sistematizada em momentos de tarefas, de obrigação; mas, de forma que a criança contextualize com a sua vivência.

Dessa forma, é imprescindível propor discussões e trabalhos práticos no meio acadêmico que enfatizem a importância da leitura na vida do escolar, como ferramenta capaz de proporcionar conhecimentos e aprendizados, relacionando o mundo em que vivemos com o currículo escolar. 


\section{Metodologia}

Essa pesquisa iniciou a partir da produção de um livro de Literatura infantojuvenil produzido na disciplina de Laboratório de Ensino de Ciências Naturais, pelos acadêmicos do curso de Ciências Biológicas da Universidade Regional Integrada do Alto Uruguai e das Missões - URI/Santiago, intitulado "Uma história nada comum: viaje no mundo dos vertebrados", com ISBN 978-85-5808-052-1.

O livro é uma ferramenta didática, produzida de forma conjunta, sendo cada capítulo escrito em duplas. Para a produção levou-se aproximadamente 3 meses. Conta a história de um grupo de alunos que, coordenados pela professora de Ciências, realizam uma visita à Floresta Nacional (FLONA) e a praia de Cassino em Rio Grande/RS, tendo contato com a flora e fauna local, relata de maneira criativa e didática a história de alguns dos animais encontrados no Rio Grande do Sul, tais como, escorpião; cobras; sapos; quero-quero; coruja; jaguatirica; raposa e peixes.

O livro produzido serviu para os acadêmicos trabalhar durante os estágios curriculares e as práticas de extensão e para os mesmos compreenderem a importância da utilização de diferentes metodologias para que o ensino de Ciências se tornasse significativo e proporcionasse novas descobertas, além de abordar conhecimento científico, enfatiza a questão ambiental.

Dessa forma foi realizada uma pesquisa qualitativa, com os acadêmicos que participaram da produção do livro didático, na qual foi utilizado um questionário, via Google forms, constando três perguntas referentes a satisfação, importância e compreensão em relação a essa ferramenta didática para o ensino. Após, ocorreu a produção de gráficos com a planilha Microsoft Excel para análise das respostas.

\section{Resultados e discussão}

Segue resultados obtidos através do preenchimento do questionário. Importante salientar que o livro foi produzido por 15 acadêmicos, porém tivemos algumas desistências no Curso, e participaram da pesquisa 12 discentes.

A tabela 1 faz referência a proposta de utilizar a literatura infantil e está relacionada ao seguinte questionamento: Você achou a proposta de literatura infantil significativa?

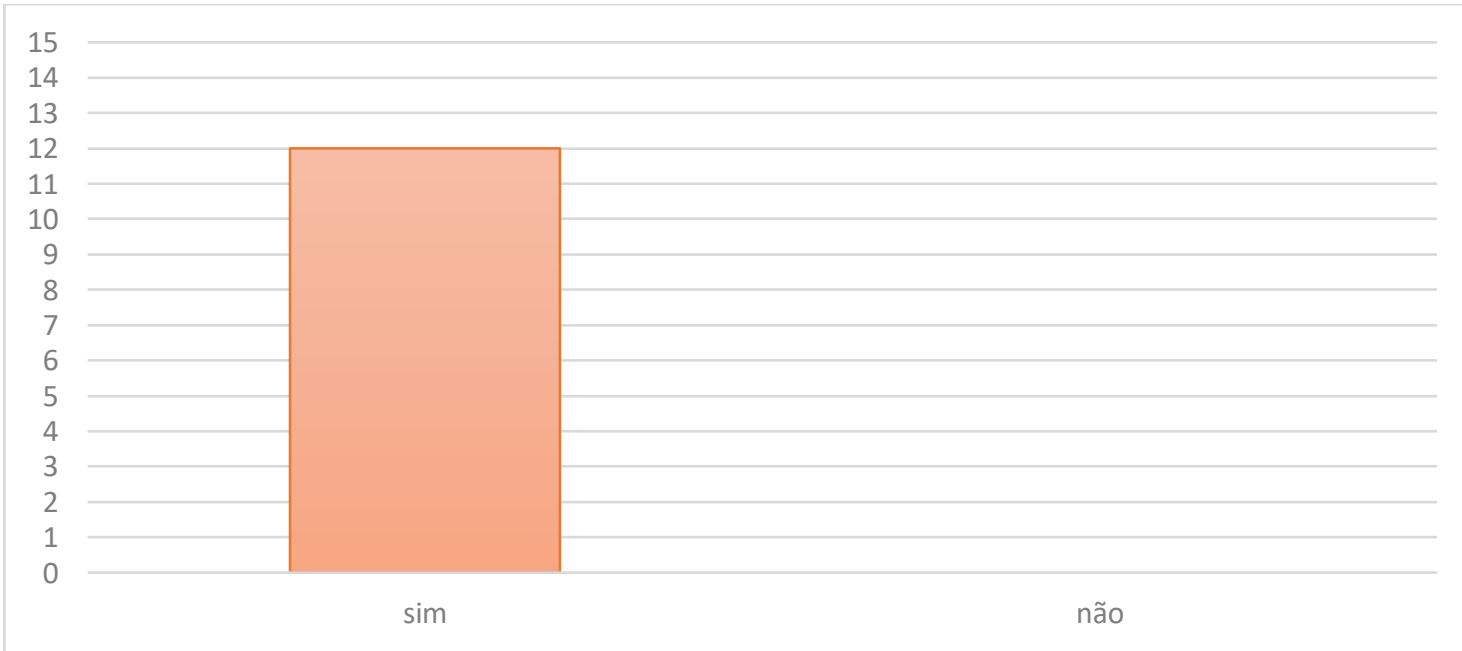

Figura 1 - Literatura infantil como uma proposta didática. (Fonte. AUTORAS, 2021) 
Percebe-se que $100 \%$ dos acadêmicos acreditam que a proposta do livro didático foi significativa. Acreditamos que as disciplinas didáticas e o manuseio da atual Base Nacional Comum Curricular (BNCC) e os Parâmetros Curriculares Nacionais (PCNs), comum em cursos de Licenciatura, auxiliem o entendimento da busca por novas formas de estimular o discente a aprender, pela compreensão dos conhecimentos científicos vislumbrados no currículo escolar.

Quando o recurso utilizado demonstra resultados positivos, o aluno torna-se mais confiante, capaz de se interessar por novas situações de aprendizagem e de construir conhecimentos mais complexos (NICOLA; PANIZ, 2016).

Para auxiliar a discussão, seguem relatos acadêmicos em relação a atividade: "retomada de conteúdo, aprofundamento de conceitos", "pesquisa relacionada a animais do Bioma Pampa", "possibilidade de intercâmbio entre conhecimentos vistos na Universidade com a comunidade", "extensão acadêmica, oportunidade de integrar o Curso de Ciências Biológicas com as escolas"; "demonstrar a importância do conhecimento do nicho ecológico dos diferentes animais"; "proporcionar respeito, conhecimento e compreensão da importância dos animais no meio ambiente"; "Trabalhar Educação Ambiental em diferentes espaços formais", "reconhecer o nicho ecológico dos animais para preservação"; "auxiliar o desenvolvimento do respeito e preservação as espécies", "auxiliar os docentes para trabalhar Educação Ambiental".

Nota-se que os relatos estão relacionados em sua maioria com a necessidade de vincular a teoria e prática, agregando conceitos, proporcionando respeito e curiosidade as diferentes formas de vida. Bacich, Tanzi Neto e Trevisani (2015) observam que o currículo e a aprendizagem são narrativas que também se constroem ao longo do percurso, em contraposição às narrativas prontas, definidas previamente. Cada um de nós vai construindo seu projeto de vida na fluência de uma rica trama de trocas, reflexões, vivências, que se interligam e recombinam incessantemente.

Sendo assim, é fundamental estimular essas trocas, reflexões e vivências, tanto para acadêmicos de Graduação, quanto para estudantes de Escolas Básicas.

A figura 2 faz uma relação dos benefícios que o livro didático traz para os alunos e para a eficácia da aula do professor, através do seguinte questionamento: Você considera que essa ferramenta didática será capaz de:

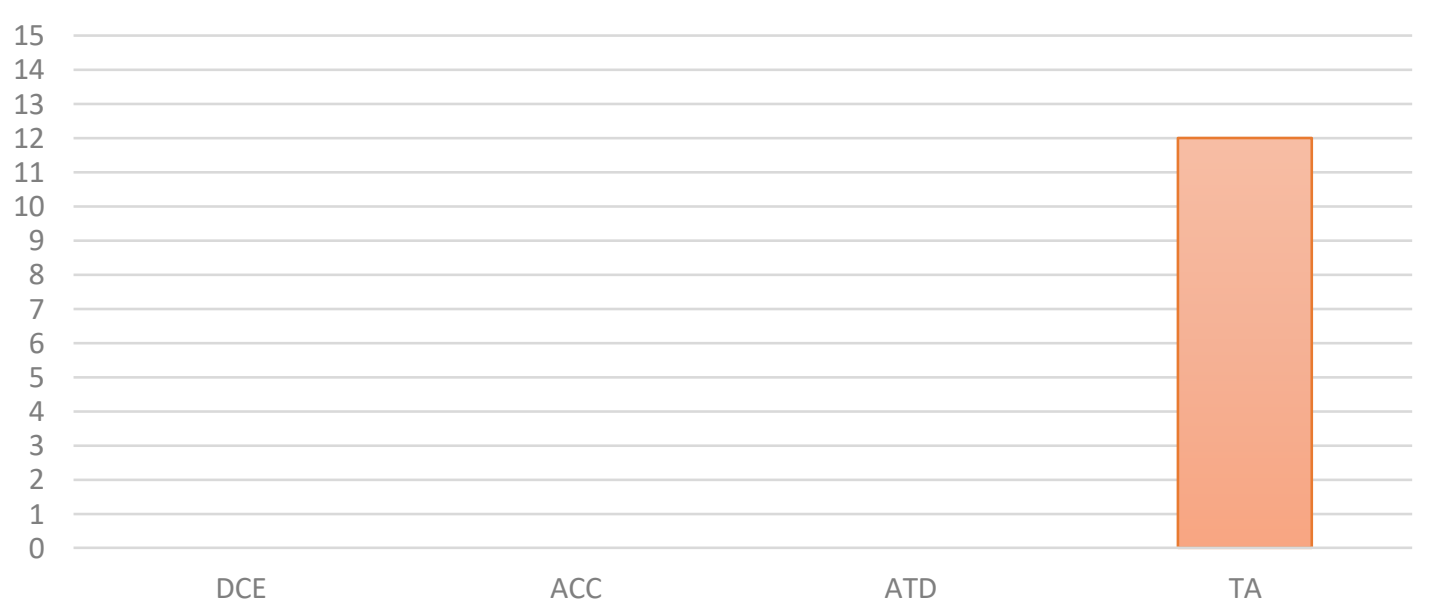

$\mathrm{DCE}=$ Definir conceitos ecológicos; $\mathrm{ACC}=$ Aprimorar conceitos científicos; $\mathrm{ATD}=$ Auxiliar trabalho docente; $\mathrm{TA}=$ todas alternativas

Figura 2 - Benefícios do livro didático para as aulas de Ciências. (Fonte. AUTORAS, 2021) 
Observa-se que 100\% dos acadêmicos, acreditam na eficácia do livro para trabalhar conceitos relacionados à Ecologia, aproximando conhecimento científico do cotidiano e como auxílio ao trabalho docente. A atual Pandemia trouxe à tona a importância de diferentes ferramentas didáticas, já mencionadas por diversos autores como requisitos básicos para auxiliar aprendizagem.

Hoje torna-se fundamental que os alunos compreendam a ligação entre a natureza, a homeostase do meio, os desequilíbrios que podem acontecer. A compreensão do que é ensinado na escola com o cotidiano, tornou-se primordial. A BNCC (2017) observa a importância de discutir, de desenvolver a capacidade de compreensão em relação ao impacto de seu comportamento em relação aos demais; resolver conflitos, respeitar regras de convivência, identificar causas de conflitos e exercitar maneiras de resolvê-los.

E para resolvê-los, é necessário conhecer ou vivenciá-los, por isso o intuito da obra literária foi de relatar a fauna gaúcha, discutindo informações, conhecendo as características, facilitando o entendimento da relação entre equilíbrio ecológico, extinção e desastres ambientais, inserindo as informações com o conhecimento adquirido em sala de aula.

Quando estamos trabalhando esse tema no cotidiano escolar, explorando todas as disciplinas é possível "amenizar" a preocupação quanto à preservação do meio ambiente (MEDEIROS; OLIVEIRA e MENDONÇA, 2011).

Já a figura 3, traz a literatura infanto juvenil como ferramenta de apoio ao trabalho docente.

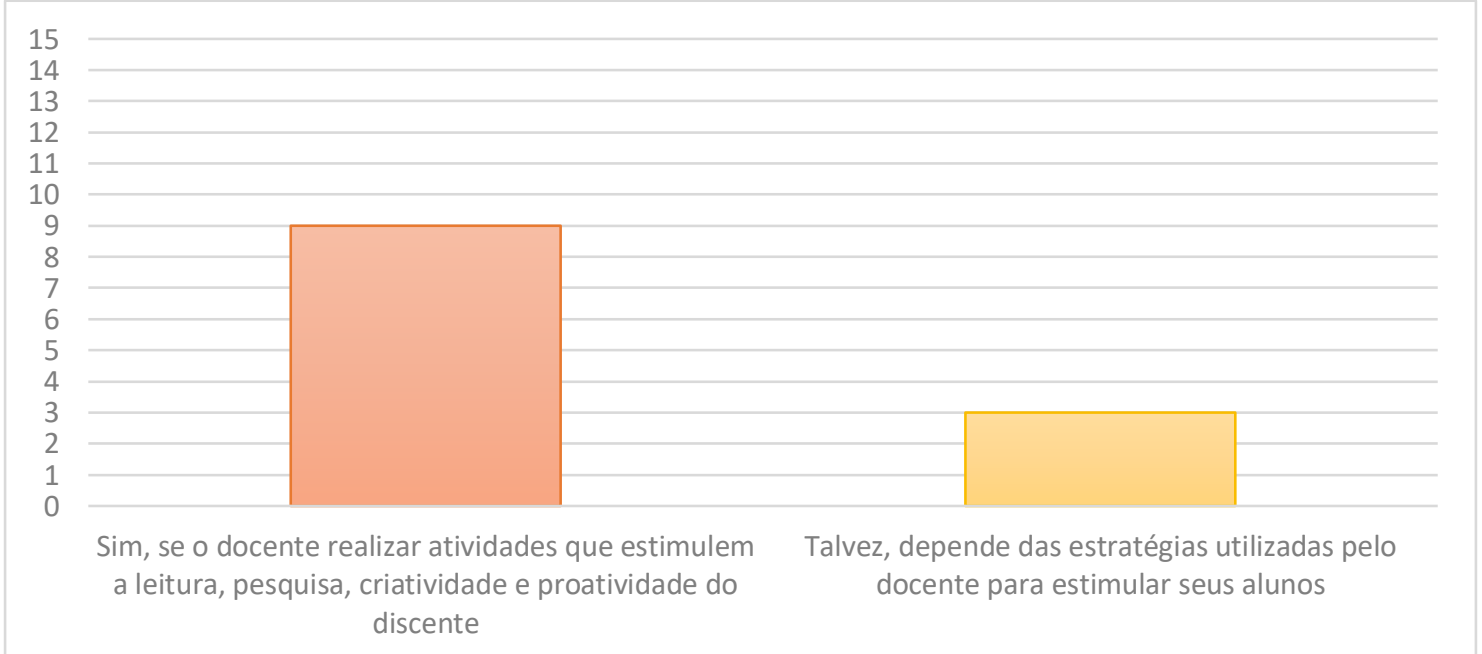

Figura 3 - Importância de ferramenta de apoio. (Fonte. AUTORAS, 2021)

A pesquisa demonstra, que os acadêmicos têm noção que a ferramenta didática só será viável, se for bem explorada pelo professor. Lembremos que a exploração, exige planejamento, leitura e análise crítica da obra. Dessa forma, o professor terá que rever posturas, atitudes e comportamentos, pois ainda acreditamos no potencial do docente para estimular, ressignificar e conduzir novas formas de aprender.

Dessa forma, a educação tem fundamental importância na formação do cidadão, de modo que possibilite o entendimento do ambiente no qual vive, desperte a capacidade crítica, como também a habilidade de tomar decisões socialmente significativas, legitimando discursos e o desenvolvimento de conhecimentos científicos (CARMO; SCHIMIN, 2008). 


\section{Considerações Finais}

Nota-se que a inserção da Literatura e da EA em conteúdos de Ciências possibilitam aos acadêmicos novas possibilidades em relação ao ensinar-aprender, proporcionam o despertar do gosto pela leitura, a imaginação, criatividade, criticidade e a percepção em relação aos desequilíbrios ambientais. Identifica-se que os acadêmicos que participaram da pesquisa, compreenderam a importância da utilização de diferentes metodologias para que o ensino de Ciências se torne significativo e proporcione novas descobertas; acreditam na eficácia da Literatura para a construção do conhecimento científico e da informação. Ainda ressaltam que as novas metodologias precisam ser muito bem trabalhadas pelos docentes, exigindo planejamento e exploração dos conteúdos.

Consequentemente, são muitas as possibilidades que a EA proporcionará, principalmente em relação aos questionamentos socioambientais e a capacidade do docente investir em propostas pedagógicas que estimulem a descoberta, a ressignificação de conceitos, a abordagem científica e principalmente a criticidade em relação a hábitos e atitudes.

\section{Agradecimentos}

A professora coordenadora da atividade e o envolvimento dos acadêmicos na produção científica.

\section{Referências}

AMARAL, Cisnara. P. et al. Uma história nada comum: viaje no mundo dos vertebrados. Santa Maria: Editora e Gráfica Curso Caxias, 2018.

BACICH, Lilian; TANZI NETO, Adolfo; TREVISANI, Fernando M. Ensino Híbrido: Personalização e tecnologia na educação. Porto Alegre: Penso, 2015.

BRASIL. Secretaria de Educação Fundamental (1998). Parâmetros Curriculares Nacionais: Ciências Naturais $-3^{\circ}$ e $4^{\circ}$ ciclos. Brasília: MEC/SEF

. Ministério da Educação (2017). Base Nacional Comum Curricular. Brasília: MEC/SEB CURRIE, Karen. Meio Ambiente: Interdisciplinaridade na Prática. 6.ed. Campinas: Papirus, 2005.

CARMO, Solange; SWHIMIN, Eliane S. O ensino da biologia através da experimentação. Curitiba: Secretaria da Educação do Paraná, 2008.

GROTO, Silvia R. Literatura de Monteiro Lobato no ensino de Ciências. 2012. Dissertação (Mestrado em Educação) - Universidade Federal do Rio Grande do Norte, Natal, 2012.

KAERCHER, Gládis S. Literatura Infantil e Educação Infantil: um grande encontro. Univesp. Disponível

em: https://acervodigital.unesp.br/bitstream/123456789/453/4/01d14t10.pdf. Acesso em: 16 mar 2021.

MEDEIROS, Aurélia B.; MENDONÇA, Maria José S.L.; SOUSA, Gláucia L.et al. A importância da educação ambiental na escola nas séries iniciais. Revista Faculdade Montes Belos, v. 4, n. 1, p. 17, 2011. 
NICOLA, Jéssica A.; PANIZ, Catiane M. A importância da utilização de diferentes recursos didáticos no ensino de biologia. Infor, Inov. Form., Rev. NEaD-Unesp, São Paulo, v. 2, n. 1, p.355-381, 2016.

PATRIARCHA-GRACIOLLI, Suelen R.; ZANON, Ângela M. Reflexões acerca da Literatura infantil e a Educação Ambiental. Educação Ambiental em ação. V.XX, n.76, 2021. Disponível em: https://www.revistaea.org/artigo.php?idartigo=2739, acesso em novembro 2021.

PELICIONI, Maria Cecília F.; PHILIPPI Jr, Arlindo. Bases Políticas, Conceituais, Filosóficas e Ideológicas da Educação Ambiental. In: PHILIPPI Jr, Arlindo; PELICIONI, Maria Cecília Focesi. Educação Ambiental e Sustentabilidade. Barueri: Manole, 2009. p. 3-12. 